\section{$\underset{\substack{\text { hommes } \\ \text { \& migrations }}}{ }$}

\section{Hommes \& migrations}

Revue française de référence sur les dynamiques

migratoires

\section{9 | 2009}

L'Afrique en mouvement

\title{
Ken Bugul, Mes hommes à moi
}

Paris, Présence Africaine, 2008, 18 euros

\section{Nicolas Treiber}

\section{(2) OpenEdition \\ 1 Journals}

Édition électronique

URL : http://journals.openedition.org/hommesmigrations/363

DOI : 10.4000/hommesmigrations.363

ISSN : 2262-3353

Éditeur

Musée national de l'histoire de l'immigration

Édition imprimée

Date de publication : 1 mai 2009

Pagination : 210

ISSN : 1142-852X

\section{Référence électronique}

Nicolas Treiber, « Ken Bugul, Mes hommes à moi », Hommes \& migrations [En ligne], 1279 | 2009, mis en ligne le 29 mai 2013, consulté le 24 septembre 2020. URL : http://journals.openedition.org/

hommesmigrations/363 ; DOI : https://doi.org/10.4000/hommesmigrations.363

Ce document a été généré automatiquement le 24 septembre 2020.

Tous droits réservés 


\title{
Ken Bugul, Mes hommes à moi
}

\author{
Paris, Présence Africaine, 2008, 18 euros
}

\author{
Nicolas Treiber
}

\section{RÉFÉRENCE}

Ken Bugul - Mes hommes à moi, Paris, Présence Africaine, 2008, 18 euros

1 Entre un bar de quartier de la rue Voltaire à Paris et la région de Thiès à l'ouest de Dakar, il y a un peu moins qu'un monde. Il y a une vie, prise dans une distance spatiale et historique. Une vie que Ken Bugul ne cesse de redéployer, dans ce qui l'a rendue, ici et maintenant, voyageuse insatiable, amoureuse de tango et de matins bleus. Après Le baobab fou, De l'autre côté du regard ou Riwan..., l'écrivain sénégalaise continue d'esquisser, avec Mes hommes à moi, les contours d'une existence passionnée qui s'est construite entre Sunugal et Tougueul, le Sénégal, la France ou ailleurs. Peut-être la sienne, entre révolte et aliénation, avec et contre les hommes.

2 Un bar donc, celui de Max, à deux pas de la place Léon Blum. Des habitués, un couple qui joue aux cartes, une dame âgée assise dans un coin, un homme accoudé au comptoir. Et une femme qui aime déambuler dans Paris comme sur les trottoirs de Dakar, qui goûte l'atmosphère des bars pour ce qu'ils sont: des carrefours de rêves et de désillusions. Une chambre d'échos idéale pour sa confession. L'histoire d'une émancipation forcenée.

3 Née au sortir de la guerre, durant la grande grève des cheminots de la ligne DakarNiger, Ken Bugul est une enfant de l'époque coloniale. Un produit pourrait-on dire, tant elle en a intériorisé les impasses. "Comment un colonisé, un assimilé, qui avait été formaté dans un statut de dominé, pouvait-il assimiler des choses, sans qu'il n'y ait aucune incidence sur son comportement". Dans toute son oeuvre, la lauréate du Grand Prix littéraire de l'Afrique noire en $1999^{1}$, s'emploie à mettre au jour les raisons de ce déracinement initial et ses conséquences. L'école coloniale a peu à peu élevé une "barrière infranchissable" entre cette fillette tiraillée entre deux cultures et son milieu d'origine. Vis-à-vis des hommes, elle cherche, elle tente. Durant ses nombreux voyages en Europe, 
elle joue de l'étiquette d'"indigène", qui adhère à sa peau, dans les yeux des amateurs d'exotisme bon marché. Elle n'est pas à cours de modèles, mais sans cesse déçue par leur incarnation. Sur Mes hommes à moi plane l'ombre paternelle, le beau visage d'un vieil homme aveugle et sage : "je n'arrivais pas à trouver l'homme qui pouvait me fixer en moi-même, un homme qui serait à la fois mon père et mon frère".

4 L'écriture de Ken Bugul, intimiste et fulgurante, prend son souffle dans la quête urgente de l'unité. Cette recherche éperdue d'une identité apaisée trouvera son guide. “ Le sage que j'avais retrouvé aux origines absolues effaça, comme par miracle, tous les mauvais souvenirs de ma mémoire [...]. Il m'avait frappée avec le sceau de la réhabilitation par la spiritualité. Il m'avait déblayéle chemin qui menait à l'individualité." Au fil de ses livres, de la mise en scène du départ au retour aux sources, Ken Bugul réussit son oeuvre de réconciliation.

\section{NOTES}

1. Pour Riwan ou le chemin de sable, Paris, Présence Africaine, 1994. 